\title{
Nova economia e Território: um estudo das tecnologias da informação
}

\author{
New Economy and Territory: a study of information technologies
}

\section{Giovana Mendes de Oliveira ${ }^{1}$}

\begin{abstract}
Palavras-chave:
Concentração

Informação

Conhecimento

Serviços

Cidades

Resumo:

A discussão apresentada aqui está relacionada ao território e às atividades econômicas. Nesse contexto, a globalização produziu uma nova economia na qual a competitividade precisa da informação, do conhecimento, das tecnologias, e o território precisa de conteúdos que propiciem esses elementos. O trabalho tem foco nas tecnologias de informação (TI), que são tecnologias importantes para formação do mundo global e para as transformações em todos os âmbitos da sociedade. Existe um esforço para definir melhor esta atividade, que já nasce digital e flexibiliza tempos e espaço, construindo sua geografia. Assim, busca-se localizar as atividades de TI e descortinar as características deste território em que ela está fixada. O recorte de análise é o Rio Grande do Sul, e a classificação da TI parte da Classificação Nacional de Atividades Econômicas-CNAE, e se utiliza de dados da Relação Anual de Informação Social-RAIS e, com isto, obtêm-se dados absolutos das empresas e dos empregados no Estado. É uma pesquisa baseada em dados quantitativos, na qual se utilizam informações de bancos de dados nacionais para estruturar as conclusões, softwares estatísticos auxiliam as análises e a pesquisa está apoiada em cartografias, gráficos e quadros, elaboradas pela própria pesquisa. Como resultados, temos a concentração geográfica dessas atividades, e os territórios em que elas se instalam são carregados de ciência e tecnologia, infraestrutura e capital. O que anuncia desigualdades territoriais e uma hegemonização de processos no mundo, no qual as metrópoles parecem ser as ganhadoras.

\section{Keywords: \\ Concentration \\ Information \\ Knowledge \\ Services \\ Cities}

Abstract:

The discussion presented here is related to the territory and the economic activities. In this context, globalization has produced a new economy in which competitiveness needs information, knowledge, technologies, and the territory needs content that provides these elements. Study has focus on the Information Technologies (IT), which are important technologies for the formation of global world and for the changes in all areas of society. There is an effort to better define this activity, which is already born digital and makes time and space more flexible, building its geography. Thus, it seeks to locate IT activities and unveil the characteristics of this territory in which it is located. The analysis part is Rio Grande do Sul, and IT classification is based on the National Classification of Economic Activities-CNAE, and uses data from the Annual List of Social Information-RAIS and, with this, absolute data are obtained from companies and employees in the state. This study is based on quantitative data, in which information from national databases is used to structure conclusions, statistical softwares help the analyzes and the study is supported by cartographies, graphs and tables, elaborated by the study itself. As a result, we have geographical concentration of these activities, and the territories in which they are installed are loaded with science and technology, infrastructure and capital, that announces territorial inequalities and a hegemonization of processes in the world, in which the metropolises seem to be the winners.
\end{abstract}

\section{INTRODUÇÃO}

Após a Segunda Guerra Mundial, uma transformação na natureza do Capitalismo começou a ocorrer, levando a uma fase importante, o Capitalismo globalizado. Esse período é caracterizado por uma mudança da produção industrial em direção a serviços, o que permitiu a diminuição da necessidade intensiva de mão de obra, embora a produção não tenha parado de se expandir, isto porque se acentua a sofisticação dos processos de fabricação, agora intensivos em tecnologia,

${ }^{1}$ Universidade Federal de Pelotas, Departamento de Geografia, Pelotas, RS, Brasil. geoliveira.ufpel@gmail.com 
possibilitando que a mão de obra humana fosse, em diversas atividades, substituída pela máquina. As margens de lucro dentro dos mercados convencionais estreitaram, e muitos empreendimentos passaram a seguir mercados especializados, sendo que essa especialização exigiu um sistema de produção flexível.

Uma das forças motrizes por trás do crescimento durante essa fase do Capitalismo foi a economia da informação e conhecimento, ou seja, uma forma de produção e gestão em que a produtividade e a competitividade dependem fortemente da geração de conhecimento e do acesso à rápida assimilação do novo. A globalização congregou e estimulou o desenvolvimento de tecnologias materiais e imateriais, que, ao potencializarem o cérebro humano, contribuíram para a criação do paradigma da sociedade da informação, do conhecimento e da aprendizagem, permitindo a existência de uma nova economia. A informação, o aprendizado e o conhecimento são elementos-chave nesse contexto. Assim, Lundval e Borrás (1998) nomeiam o processo como economia do aprendizado.

E, assim, hoje, informação e conhecimento devem estar em sintonia com a inovação, pois esta requer que ideias novas não aconteçam apenas em momentos crise, ou seja, deve-se pensar na crise como cotidiano.

A inovação deve acontecer continuamente, o que exige competividade para que processos e produtos possam sempre ser revistos e orientados para gerar inovações, e porque o mercado flexível mudou rapidamente. E a coleta de informação, e a transformação destas em inovações, leva a empresa a estar em constante aprendizado. Aprendizado este que não está apenas em aprender com conhecimentos codificados (ou explícitos), mas também com os tácitos. Nonoka e Takeuchi (2008, p. 18) definem o conhecimento codificado ou explícito como um conhecimento que "pode ser expresso em palavras, números, sons, e compartilhado na forma de dados, fórmulas científicas, recursos visuais, fitas de áudio, especificações de produtos e manuais. $\mathrm{O}$ conhecimento explícito pode ser rapidamente transmitido aos indivíduos, formal e sistematicamente". É um conhecimento que pode ser rapidamente difundido pelas redes. O conhecimento tácito, segundo Nonoka e Takeuchi (2008, p. 18), "não é facilmente visível e explicável. Pelo contrário, é altamente pessoal e difícil de formalizar, tornando-se a comunicação e compartilhamento dificultoso. As intuições e os palpites subjetivos estão sob a rubrica do conhecimento tácito". É um conhecimento ligado à experiência, que, muitas vezes, mesmo quem o detém não tem como explicitar. Assim, o conhecimento tácito tende a ser extremamente territorializado.

É diante desse panorama que surgem afirmativas sobre o retorno ao território ou a força dos territórios. Dadas as várias acepções do conceito, cabe esclarecer que território é entendido como resultado das relações de poder, como nos aponta Raffestin (2011). O poder tende à dominação e ao controle, e este se materializa no espaço, formando o território, que abriga vários recursos, não vistos apenas como matérias-primas, mas como infraestrutura, população e informação, conhecimento e capacidade de aprendizagem. Ao se constituir o território, os atores produzem uma territorialidade marcada por símbolos, ideias, costumes, permitindo a posse e o domínio de determinado grupo. Hoje, o território ganha um olhar mais atento da comunidade científica, porque ele é importante promotor da inovação. Segundo Helder Santos:

o território deixa de ser um espaço valorizado apenas pelos seus aspectos quantitativos, deixando de ser visto como uma mera plataforma física (onde assentam os recursos e infraestruturas materiais), para passar a assumir um carácter de espaço vivo e vivido onde os aspectos qualitativos, imateriais e intangíveis, de densidade das redes relacionais e profundidade das relações de conhecimento/aprendizagem assumem um papel central e conferem espessura ao território. (SANTOS, 2009, p. 293).

Na sociedade atual, os territórios nos quais os atores conseguem se organizar de forma a conseguirem sinergia e aproveitarem ao máximo os recursos materiais e imateriais, tornam-se aglomerações competitivas, ou seja, passam a disputar a concorrência nos mercados globais. Ainda que os territórios possam operar em redes, é no território zona que se facilita a proximidade, construindo uma atmosfera para inovação.

Nesse processo, são as cidades, em especial, os grandes centros, que têm concentrado estes espaços competitivos, em que a inovação e o empreendedorismo são maiores.

O que identifica esta nova dinâmica econômica é uma busca, cada vez maior, pela inovação para garantir a competitividade, e, para isto, existe a necessidade de construir um ecossistema no qual informação e aprendizagem sejam constantes, para que o conhecimento gerado se transforme em inovação. São as grandes cidades, na maior parte do mundo, as metropolitanas, que abrigam as condições para que esse processo seja possível. Segundo Méndez:

Perviven así fuertes ventajas competitivas para las metrópolis, tanto por el volumen de externalidades asociado al tamaño de sus mercados (de consumo, trabajo y capital), como por la densidad y calidad de sus infraestructuras físicas (desde vías de transporte de gran capacidad y aeropuertos internacionales, a plataformas logísticas, telepuertos, etc.) y, sobre todo, por toda una serie de recursos específicos hoy valorados como estratégicos. Éstos incluyen un capital humano cualificado, la presencia de organizaciones públicas y privadas generadoras o difusoras de conocimiento, así como un marco institucional generalmente favorable -al menos en términos comparativos con otros territorios-al intercambio de información, la apertura externa y la conformación de clusters empresariales y redes sociales potenciadoras de la innovación, con la 
aparición de rendimientos crecientes de escala. (MÉDEZ, 2007, p. 54).

Stoper (2005) aponta, também, que estas cidades permitem garantir o burburinho, que é o barulho advindo do contato face-to-face, que, para o autor, permite a transmissão de conhecimentos não codificáveis, os tácitos. O contato face-to-face é um meio de superar problemas de coordenação e incentivo em ambientes incertos, e um elemento-chave da socialização que, por sua vez, permite que as pessoas façam parte de grupos; e, da mesma forma, uma fonte direta de motivação psicológica.

Assim, o que se percebe é que, para inovação, é importante a concentração de pessoas, capital, e presença de ciência e tecnologia. É preciso aglomerar quem deseja inovar, e quem precisa das inovações e da qualidade dos equipamentos urbanos, mas também do face-to-face. Stoper (2005) considera que a força econômica das cidades esteja no burburinho produzido pelo face-to-face, porém, como aponta Asheim (2016), ele ainda está pouco definido. Diante da indefinição, é possível contribuições, e parece-nos que este conceito pode ser alargado, pois burburinho é composto não só pela presença de face-to-face, mas também para territórios ou cidades que contenham concentração de pessoas, capital, e presença de ciência e tecnologia, de quem deseja inovar, e de quem precisa das inovações e da qualidade dos equipamentos urbanos. $\mathrm{O}$ burburinho parece-nos que seja o barulho de tudo isto acontecendo, está mais além do contato face-to-face, é uma sinergia que envolve fatores materiais, como infraestrutura e centros de pesquisa, mas, também, de possibilidades de encontros face-to-face. Desta forma, o território requer novos recursos que permitam circular e produzir a informação, e, assim, uma efervescência.

Se esse processo elege alguns centros, pode-se esperar que as desigualdades territoriais se acentuem, prejudicando a coesão social. Se isto é preocupante em países centrais, mais preocupantes se tornam ao analisarmos as realidades dos países semiperiféricos. A União Europeia, que apostou na intensificação de estratégias para promover a entrada de seus membros na sociedade da informação, do conhecimento e da aprendizagem, tem se preocupado com a questão das desigualdades entre os membros de sua comunidade e tem apontado para estratégias que diminuam essa situação. Dentre essas estratégias, está a adoção de propostas de smart specialization que procuram orientar a economia para que se valorizem os pontos fortes de cada região.

Estudos da nova economia precisam ser elaborados para entendermos suas consequências em países semiperiféricos como o Brasil, pois problemas de coesão territorial e social são mais sérios em países que já enfrentam históricas questões sociais e territoriais.

$\mathrm{O}$ estudo em questão investiga as tecnologias da informação, em primeiro lugar, mostrando sua geografia e, após, buscando as razões para tal geografia. Para o primeiro item, se utilizam dados sobre empregos e empresas de TI, para o segundo, são utilizadas variáveis que possam revelar os motivos desta geografia. Assim, apresentam-se dados sobre a localização das empresas de TI, dos empregadores de TI e a relação da presença de TI nestes locais com as variáveis, infraestrutura, cursos superiores na área de Tecnologias da Informação, registros de programas de computadores e disponibilidades de velocidade de Internet. Os dados apresentados são prioritariamente quantitativos e partem da base de dados da Relação Anual de Informações Sociais-RAIS, utilizando-se como referência o ano de 2016, contudo, são pautados por vários diálogos com profissionais que trabalham com TI. As outras informações são de dados do Instituto Brasileiro de Geografia e Estatística-IBGE; do Instituto Nacional Propriedade Intelectual-INPI; do Censo Educação Superior do Ministério da Educação, do Instituto Nacional de Estudos e Estatísticas Educacionais Anísio Teixeira - INEP, e da Agência Nacional de Telecomunicações - ANATEL, nos anos disponíveis (2010-2017). Para se obterem as informações, os dados foram tratados com softwares Excel e SPSS. As figuras foram construídos a partir do software Arcgis.

O recorte de análise é o Estado do Rio Grande do Sul, extremo Sul do Brasil, fazendo fronteira com o Uruguai e Argentina, e sua capital é Porto Alegre, situada a Leste do Estado.

\section{UMA TENTATIVA DE CARACTERIZAÇÃO DAS ATIVIDADES DE TI}

A TI é um segmento do setor dos serviços de difícil definição, os próprios profissionais acreditam que ela se renova o tempo todo e qualificar o que realmente é torna-se um risco, pois se pode menosprezar alguma atividade que esteja surgindo. Contudo, as TIs podem ser caracterizadas por atividades de serviços de informação. Elas geram e colocam em circulação a informação e, ao potencializarem o cérebro humano, aceleraram a capacidade de pensar e armazenar conhecimentos, permitindo que ideias gerem novidades. Ao mesmo tempo, possibilitam a circulação dos conhecimentos codificados e, em alguns casos, até o mesmo o tácito, tornando novidades rapidamente em coisas obsoletas, o que denota o poder desta tecnologia para a inovação. Essas tecnologias permitem a integração entre empresas possibilitando uma operação internacional quase instantânea, um carro é vendido em um país e, em outro, é disparada, via Web, a necessidade de produção de determinadas peças, isto tudo permite que competitividade e lucratividade aumentem.

As atividades oficialmente caracterizam-se como serviços, pois é, muitas vezes, intangível e invisível, contudo, existe uma discussão sobre esse tema, como aponta Kon (2004). Os serviços estão estreitamente ligados à indústria; como exemplo, pode-se citar a tecnologia embarcada, que são sistemas de software e hardware que existem dentro de carros, geladeiras, 
videogames, aviões, etc., como é o caso da telemetria, sistema que lê dados do veículo e repassa para uma central que tem informações sobre as condições do veículo. $\mathrm{E}$ estes produtos aparecem como manufaturados, produtos da indústria, mas seu diferencial vem da tecnologia embarcada. Também podemos citar alguns produtores de softwares não customizáveis, que consideram seu produto ligado à indústria, uma vez que vendem cópias desse produto reaplicáveis aos seus usuários. Esta discussão dos serviços é muito importante em um mundo cujos setores econômicos, cada vez mais, se voltam para o intangível, pois o seu peso na economia pode estar subestimado.

E deve-se ressaltar que não estamos discutindo atividades econômicas com mais alto poder de gerar riquezas, ainda não. Esta afirmação é baseada em dados como da empresa Fortune, na qual é apresentado o ranking das maiores empresas do mundo por faturamento, nos dados apresentados em 2017, entre as 11 primeiras empresas, a Apple aparece no ramo de tecnologia no $11^{\circ}$ lugar. Por outro lado, no ranking no qual são apresentadas as empresas que crescem rápido, entre dez, seis empresas são de tecnologia.

A classificação adotada pela pesquisa para definir TI segue aquela utilizada pela Classificação Nacional de Atividades Econômicas - CNAE, na qual ela é definida dentro do setor de serviços envolvendo as atividades apontadas na Quadro 1:

Quadro 1: Serviços e prestação de serviços em TI segundo CNAE -CLASSE, 2.0.

\begin{tabular}{|l|}
\hline \multicolumn{1}{|c|}{ Atividades de serviços e prestação serviços } \\
\hline 1. Desenvolvimento de Programas de Computador sob Encomenda. \\
2. Desenvolvimento e Licenciamento de Programas de Computador Customizáveis. \\
3. Desenvolvimento e Licenciamento de Programas de Computador Não Customizáveis. \\
4. Consultoria em Tecnologia da Informação. \\
5. Suporte Técnico, Manutenção e outros serviços em TI. \\
6. Tratamento de dados, Provedores de serviços de aplicação e serviços de hospedagem na Internet. \\
7. Portais, Provedores de conteúdo e outros serviços de informação na Internet. \\
8. Outras atividades de prestação de serviços.
\end{tabular}
Fonte: CONCLA (2006); IBGE (2016).

Analisando as características que envolvem as atividades, é possível classificá-las como potencialmente inovadoras ou rotineiras. As atividades inovadoras são aquelas que envolvem desenvolvimento de softwares, tanto customizáveis como não customizáveis. Junto aos desenvolvimentos, foram consideradas como potencialmente inovadoras aquelas atividades de consultoria, pois envolvem possibilidades de gerarem produtos novos na orientação de empresas. Estas são aquelas que geram produtos novos para desenvolvimento do mercado. As atividades rotineiras são as que envolvem operações em produtos já existentes, envolvendo os itens 5 a 8 da Quadro 1 .

A referida atividade, no Brasil, tem início no final do século passado e ocupou em 2017, segundo dados das Contas Nacionais Trimestrais-CNT do IBGE, 2,7\% do Produto Interno Bruto (PIB) nacional. Esses números mostram que ele não tem grande peso na formação do capital nacional, mas que vem crescendo. Em 2010, o valor total da produção deste segmento, em preços correntes, segundo da CNT do IBGE (2018), significou R\$ 126.542 milhões; em 2017, foram R\$ 180.200 milhões, o que mostra uma taxa de crescimento de $42 \%$ deste segmento.

A TI é uma atividade econômica que envolve qualificação. Entre profissionais da área, é ressaltado que o conteúdo-base discutido nos cursos superiores é fundamental, mas não é apenas isto, o profissional dessa área deve estar em constante aperfeiçoamento em comunidades de aprendizagem formais ou informais. Nisto reside a importância da network, que é fundamental para contatos de trabalho e para desenvolver aprendizagens para superar novos desafios resultantes da constante evolução da atividade.
Estudos de Oliveira (2014, 2016 e 2018) e Pereira e Oliveira (2020), revelam que a TI envolve firmas que ocupam poucos espaços; são empresas limpas, seu resíduo assemelha-se a um escritório comum; possibilitam a terceirização, trabalham com um grupo de empregados, mas podem facilmente operar com outra empresa que esteja em outro país, já que operam a distância, flexibilizando tempo e espaço, permitindonos comunicações síncronas e assíncronas.

Esta relação de possibilidade listada anteriormente permite dizer que tais atividades apontam para uma possibilidade de localização variada, inclusive com fortes descentralizações. Não obstante, não é o que se encontra no estudo que se apresenta a seguir.

\section{TI no Rio Grande do Sul (RS): a localização concentrada}

A TI no Rio Grande do Sul tem permanecido tímida como no Brasil, mas tem sofrido um pequeno crescimento, uma vez que, segundo dados das CNT do IBGE, entre 2013 a 2015, passou de 2,4 para 2,6 do Valor Adicionado Bruto. De acordo com a RAIS, o Rio Grande do Sul possuía 8.058 firmas em 2016, sendo que as atividades que mais compreendiam firmas eram: Suporte Técnico, Manutenção e Outros Serviços em Tecnologia da Informação (2.171); Tratamento de Dados, Provedores de Serviços de Aplicação e Serviços de Hospedagem na Internet (1.205); seguida pela atividade de Desenvolvimento de Programas de Computador sob Encomenda (1.343). As duas primeiras são atividades rotineiras, e a segunda, potencialmente inovadora. Esses são dados que revelam uma certa fragilidade na organização da TI no Rio 
Grande do Sul, pois as empresas têm uma especialização que não propicia a inovação. O que pode ser exemplificado com a Dell Computadores do Brasil Ltda., que está localizada em Guaíba, esta empresa tem uma reconhecida competência ligada à inovação, com o desenvolvimento de sistemas computacionais, mas, no RS, sua atividade principal é suporte técnico, uma atividade rotineira que limita a inovação.
Analisando a Figura 1, que apresenta os dados da localização das empresas de TI no território do Rio Grande do Sul, evidencia-se uma aglomeração de empresas no eixo Porto Alegre-Caxias do Sul, e este eixo abrange também a Região Metropolitana de Porto Alegre.

Figura 1. Localização das empresas de Tecnologias de Informação no Rio Grande do Sul, 2016.

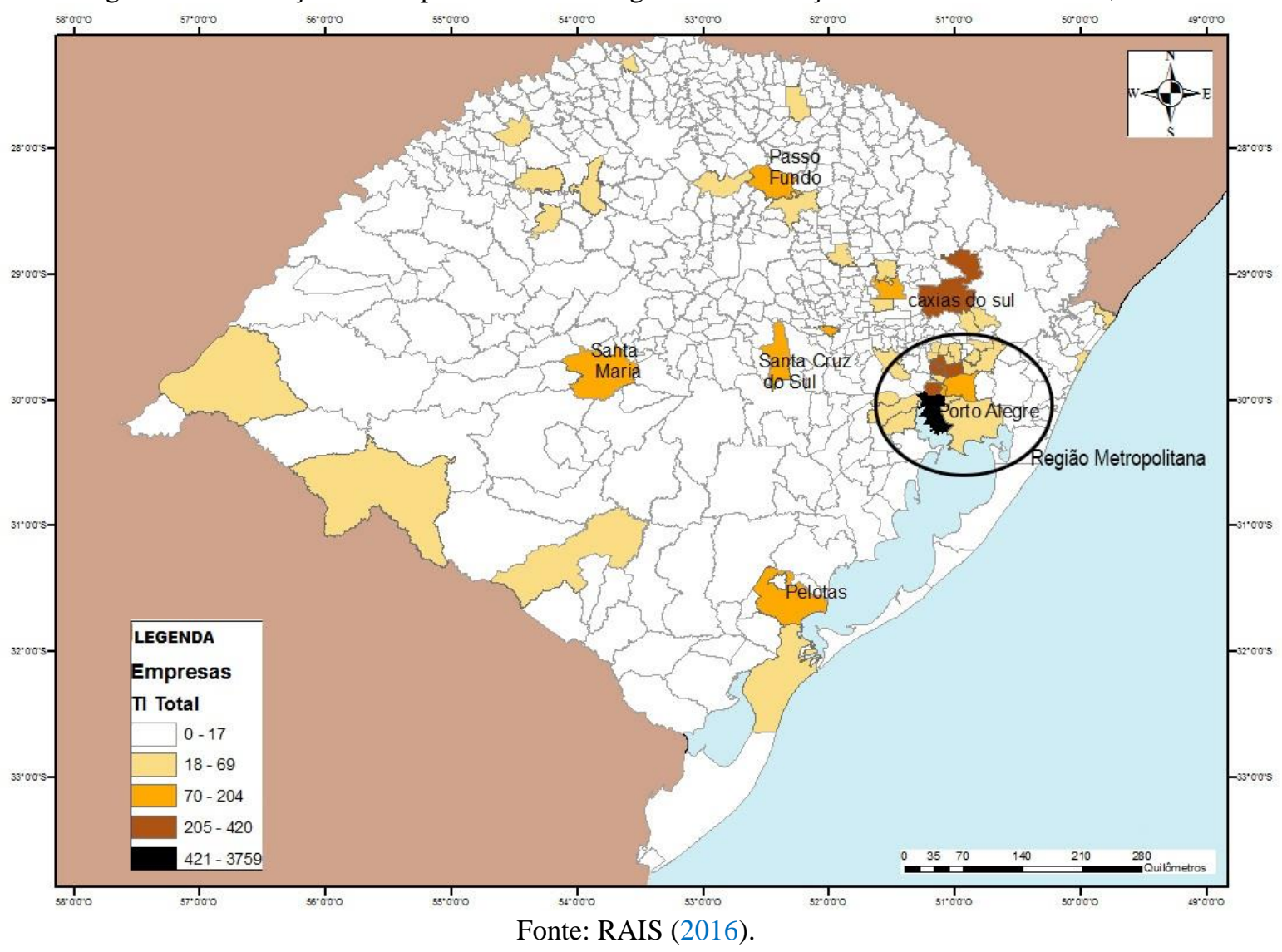

Reunindo os 20 maiores municípios que abrigam empresas de TI, eles contabilizam $82 \%$ das firmas. Porto Alegre apresenta-se como uma cidade primaz, ela é a mais importante dentro das atividades de TI, reunindo a metade das firmas de TI, uma vez que, em 2016, Porto Alegre possuía 3.759 firmas, contendo $46,6 \%$ das firmas de todo o estado. A Figura 1 revela também a importância da região metropolitana (RM), contabilizando os municípios que têm maior número de empresas de TI, em que dez delas estão na RM de Porto Alegre: Novo Hamburgo (397), Canoas (331), São Leopoldo (282), Gravataí (134), Cachoeirinha (121), Esteio (69), Montenegro (64), Campo Bom (59), Sapiranga (56) e Guaíba (49). Além da capital e da RM, os demais municípios do Rio Grande do Sul que têm atividades de TI em destaque já possuem reconhecida evidência econômica e política, como são os casos de Caxias do Sul (420), Pelotas (204), Santa Maria (142), Passo Fundo (135) e Santa Cruz (111).

Analisando-se a distribuição das atividades, não se verifica nenhuma especialização das firmas. Ou seja, as atividades rotineiras e potencialmente inovadoras ocorrem em todos os municípios; mais uma vez revelando a importância de Porto Alegre que concentra a maioria das firmas em todas as atividades de TI.

Para refinar a discussão, foram analisados os dados sobre os empregados em TI, os vínculos ativos, como denomina a Rais. Em 2016, eram 37.995 os vínculos ativos nesta atividade. Porto Alegre abrigava 21.756 empregados, $57 \%$ do total do Rio Grande do Sul. Os 20 municípios com maior número de empregados abrigavam $92 \%$ do total de empregados do Rio Grande do Sul. A região metropolitana, junto com Porto Alegre e Caxias do Sul, formando o eixo Caxias-Porto Alegre, envolvem 32.562 trabalhadores. Resultado semelhante ao apresentado anteriormente sobre as firmas de TI, revelando expressiva concentração geográfica.

A Figura 2 representa esta concentração de empregados. A diferença encontrada entre os dados de empresas e empregados em TI é que, entre os 20 municípios que detêm os maiores efetivos de empregados de TI, aparece um número maior de municípios fora do eixo Caxias-Porto Alegre, além de Passo Fundo (628), Pelotas (521), Santa Maria (352), 
Erechim (354), aparecem Casca (334), Três de Maio (160) e Marau (142). A maior parte da população empregada está em atividades potencialmente inovadoras, 20.146, contabilizando 53\% dos funcionários. Mas é importante ressaltar que a atividade que mais contém empregados é a atividade de Suporte Técnico, Manutenção e outros serviços em TI, com 7.423 trabalhadores. Nos municípios do interior, as atividades estão relacionadas tanto atividades rotineiras como potencialmente inovadoras.

Figura 2. Localização dos empregados em Tecnologias de Informação no Rio Grande do Sul, 2016.

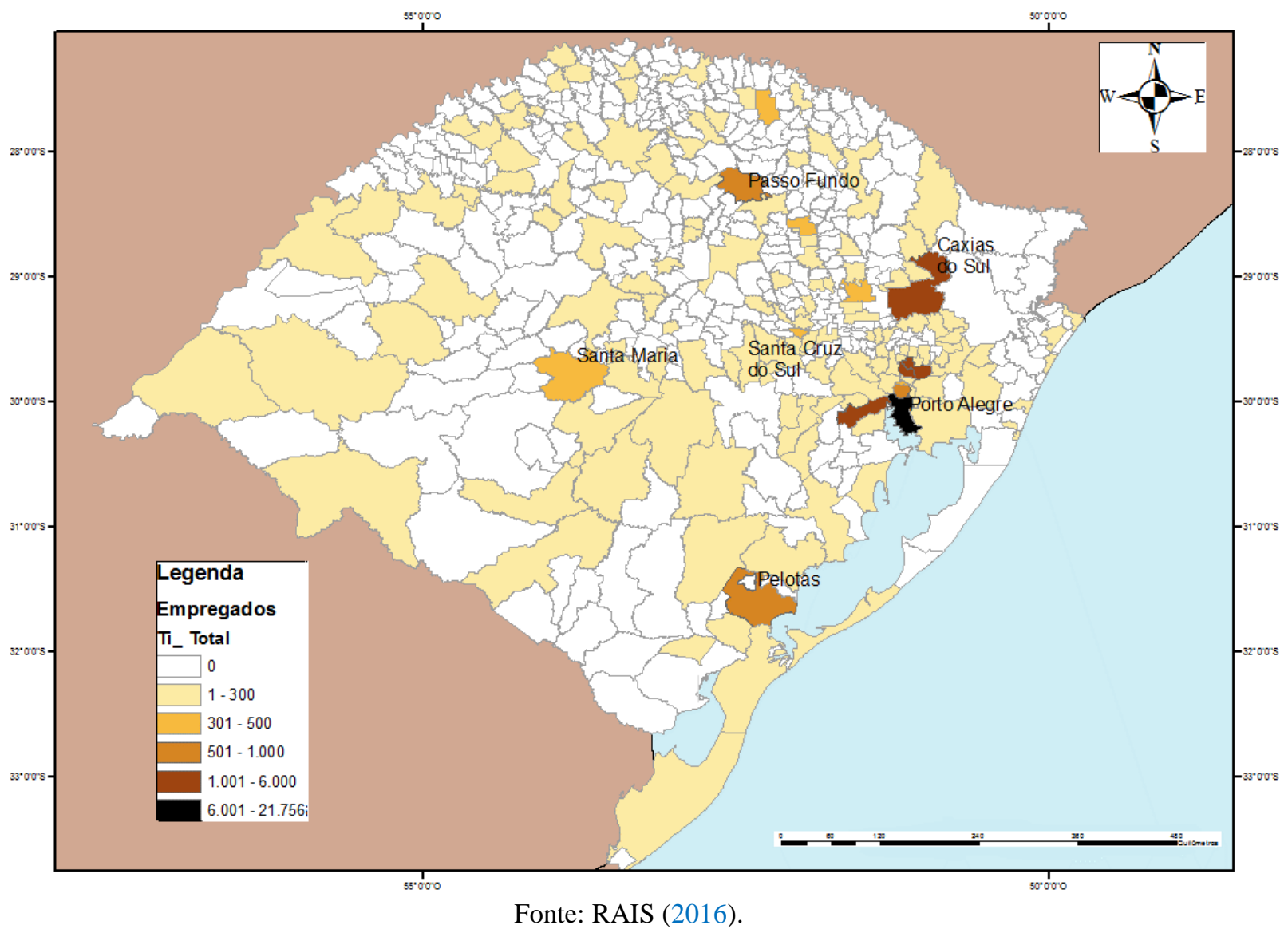

Como resultado das figuras 1 e 2 , fica evidenciada uma concentração das atividades de TI na RM de Porto Alegre, dilatando um pouco mais no eixo Caxias do SulPorto Alegre. E os municípios que se destacam fora do eixo são: Pelotas, no Sul; Santa Maria, no Centro; e Passo Fundo, no Norte, isto tanto em relação a empresas quanto, ao número de empregados. Todavia, sem dúvida, Porto Alegre é o grande centro que abriga essa atividade, reforçando o que já foi afirmado, são as cidades que abrigam as condições para que isto seja possível, em especial, aquelas que possam garantir sinergia advindo de quem deseja inovar e quem precisa das inovações.

\section{Características dos territórios em que está a concentração de TI}

Recuperando o que já foi afirmado neste texto, os territórios dentro da nova economia precisam incorporar novos recursos. A mão de obra, matériaprima e infraestrutura ainda são importantes, mas, neste século, os territórios são, ou devem ser, carregados de novos conteúdos. Cabe, neste momento, analisar estes territórios que a TI tem se servido para desenvolver suas atividades, e que formam uma aglomeração, e verificar se eles abrigam estes novos conteúdos. Neste trabalho, os novos conteúdos são apresentados como ligado a conhecimento e à informação. Estes conteúdos têm um sentido mais alargado do que apresentado por Storper, e está traduzido nas variáveis velocidade de Internet, população, PIB, centralidade urbana, registro de patentes e graduados em TI.

Presença de banda larga fixa de Internet: homogeneidade do território

A Internet é um recurso que deve estar presente no território para o desenvolvimento das atividades de TI, que, como foi aludido, opera a distância, e, para que isto ocorra, velocidade de Internet, em variadas ofertas, são imprescindíveis. Analisando os dados disponibilizados pela ANATEL, em 2016, sobre banda larga fixa de Internet, velocidades, tecnologias e empresas que ofertam Internet, constata-se que, no Rio Grande do Sul, há disponibilidade de Internet em todo território, uma vez que, em 497 municípios, são encontrados serviços 
de Internet em velocidades que variam de 512kbps a $>34$ Mbps. Selecionando-se apenas as tecnologias, Ethernet, Cable Modem, XDSL e Fibra, verifica-se que elas estão por todo território e com, pelo menos, 08 ofertas de empresas/velocidades, como é apresentado na Figura 3. Os grupos que ofertavam as tecnologias em 2016 eram Algar (CTBC Telecom), Blue, BT, GVT OI SKY/AT\&T, Telecom Américas, Telecom Itália e Telefônica. Enfocando com maior detalhe nas tecnologias, observa-se que a fibra óptica, com velocidade de mais de $34 \mathrm{Mbps}$, considerada uma tecnologia com grande eficiência, é ofertada em 413 municípios.
Mas, apesar dos municípios possuírem disponibilidade de Internet bem distribuída, o mesmo padrão não se apresenta com relação a empresas e empregos de TI, como já foi relatado. A situação de Bagé é emblemática, mesmo ao possuir velocidades acima de >34 Mbps, em fibra, e com várias empresas ofertando o serviço, não existe importância da TI neste município.

Assim, analisando-se os dados sobre oferta de Internet, verifica-se que, estar bem distribuída no Rio Grande do Sul, não pode ser considerado como um fator fundamental que permita ou reforce a concentração visualizada nas figuras 1 e 2 .

Figura 3. Disponibilidade de Internet, nas tecnologias Ethernet, Cable Modem, XDSL e Fibra no Rio Grande do Sul (todas as faixas de velocidade).

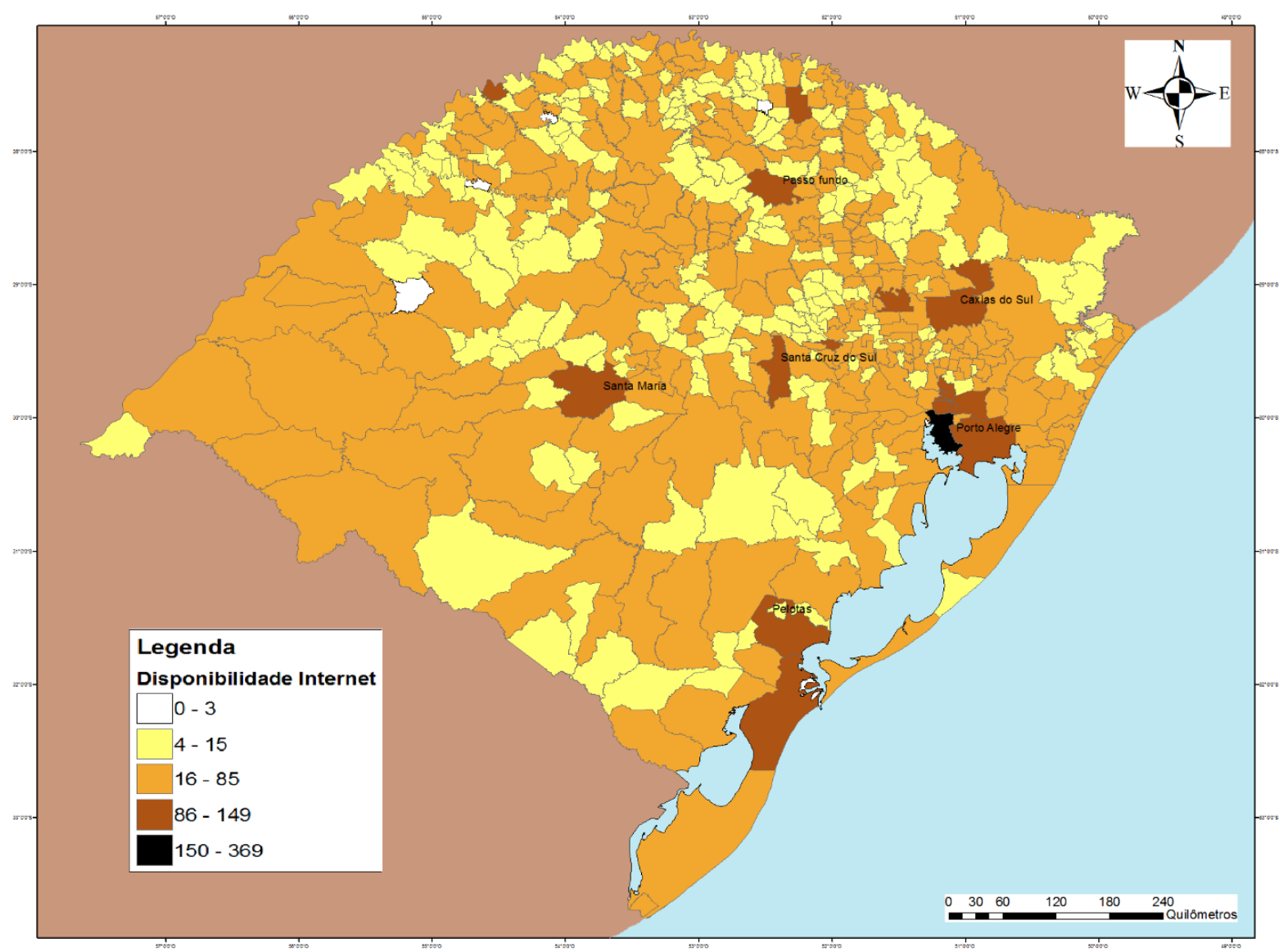

Fonte: ANATEL (2016).

Cabe ressaltar que a investigação revelou que os grupos que disponibilizam a Internet, apesar de existir infraestrutura instalada, só materializam a oferta mediante procura dos clientes, fato que explica a existência de maior oferta nos municípios com maior TI e o fato de que municípios vizinhos têm disponibilidade de Internet diferentes.

\section{População e Produto interno Bruto: concentração populacional e de capital, e a aglomeração em TI}

Considerando os dados do Censo 2010 e do PIB de 2017, verifica-se que a localização das firmas de TI envolve diretamente a concentração de população e capital. Dados da população do Rio Grande do Sul em correlação com dados de empresas em TI mostram que os 20 municípios mais populosos do Rio Grande do Sul estão na lista de maiores concentradores de empresas de TI.

Nestas aglomerações de TI, encontramos população para promover a aprendizagem e a informação, e, também, capital para que seja utilizado no desenvolvimento das atividades, e capital que necessita dos serviços nessa atividade. A população presente é um recuso fundamental, é mão de obra para trabalhar, mas também é recurso quem pensa e cria, a partir de seus conhecimentos tácitos e codificáveis, e também que precisa de inovações. É importante para gerar 
novidades e, até mesmo, para manter as atividades rotineiras em TI, que cada vez mais requerem população qualificada. $O$ capital presente neste território precisa de serviços de TI, alimenta o mercado, injeta dinheiro para que inovações sejam difundidas, financia pesquisas, e atrai novas empresas e novas pessoas.

\section{A presença de intenso registro de Programas de Computador e cursos de graduação na aglomeração}

A informação sobre concluintes de cursos de graduação em TI é importante de ser analisada no quadro da sociedade do conhecimento, que visa à inovação. Isto porque, ainda que a inovação valorize os conhecimentos tácitos, os codificáveis são fundamentais. O conhecimento codificado é apropriado ao longo do tempo na universidade e a conclusão da graduação é a solidificação de todos esses aspectos. Para prosseguir na carreira, o profissional precisa seguir estudando e, sem a síntese da graduação, tudo fica mais complexo. E, avaliando as informações sobre escolaridade na RAIS, verifica-se que a TI envolve pessoal qualificado, uma vez que $65 \%$ dos trabalhadores possuem curso superior ou estão cursando. Ainda que sejam dados tímidos, já aparecem na estatística de 2016 dados com relação a mestrado (404 trabalhadores) e doutorado (38 trabalhadores).

Figura 4. Concluintes nos Cursos de Graduação em TI no Rio Grande do Sul, 2016.

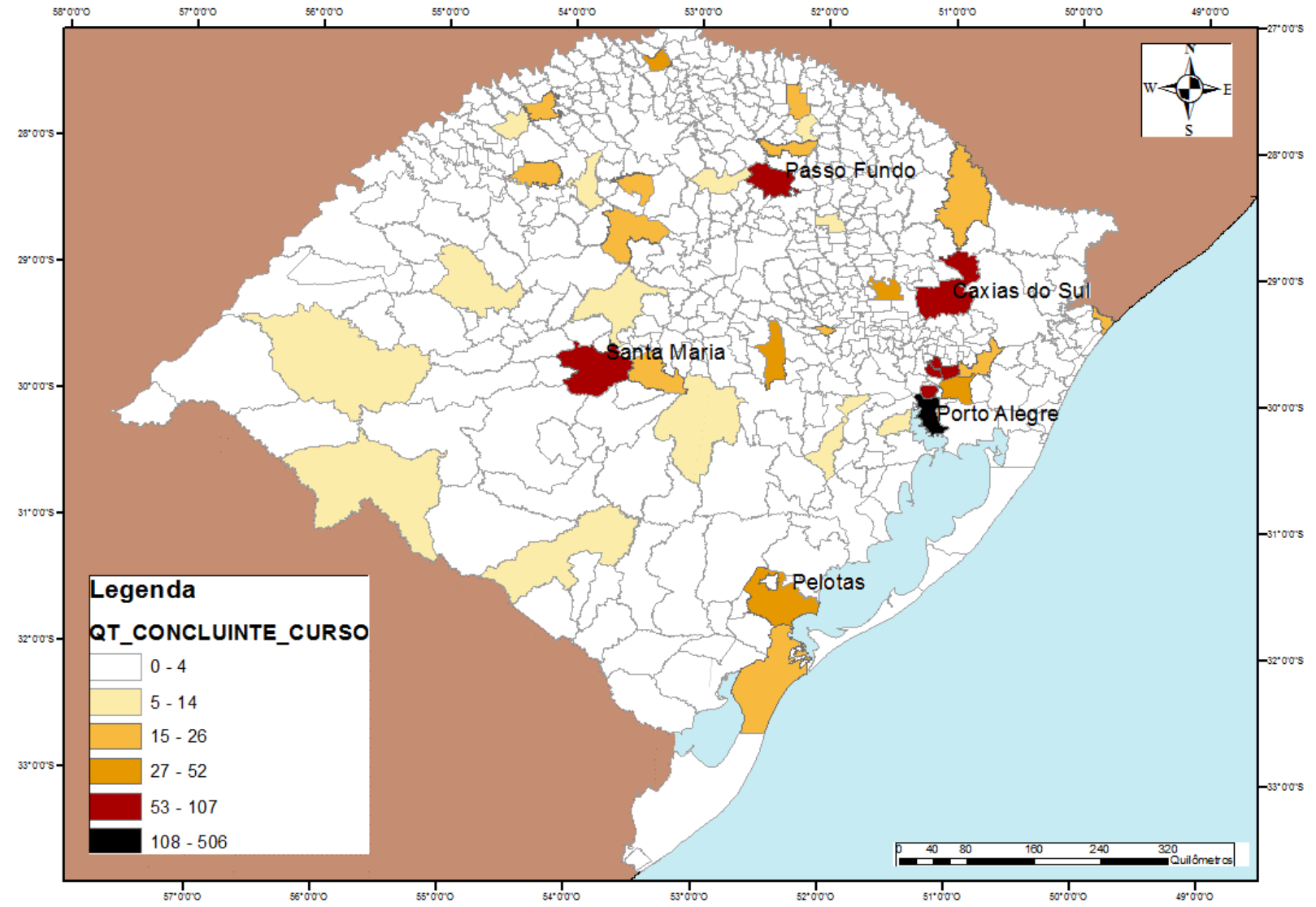

Fonte: Censo de educação superior. MEC/Inep, 2016.

A Figura 4 auxilia na avaliação da espacialização dos dados do Censo de Educação Superior. Observa-se que o maior número de graduados se localiza nos municípios que têm mais empresas de TI, e Porto Alegre fica novamente em destaque, seguida de Caxias do Sul e Novo Hamburgo. Os 10 municípios que abrigaram, em 2016, os 1.204 concluintes em cursos de
Graduação em TI equivalem a 74\% dos graduados na área.

Os registros de Programas de Computador são dados referentes aos depósitos no INPI, de pessoas ou empresas, para proteção da autoria do invento. Para uso deste trabalho, foram agregados dados de 2000-2016, e os dados ainda são tímidos, o que denota pequena inovação neste segmento do setor de serviços. 
Gráfico 1. Depósitos de Registros de Programas de Computador, 2000-2017.

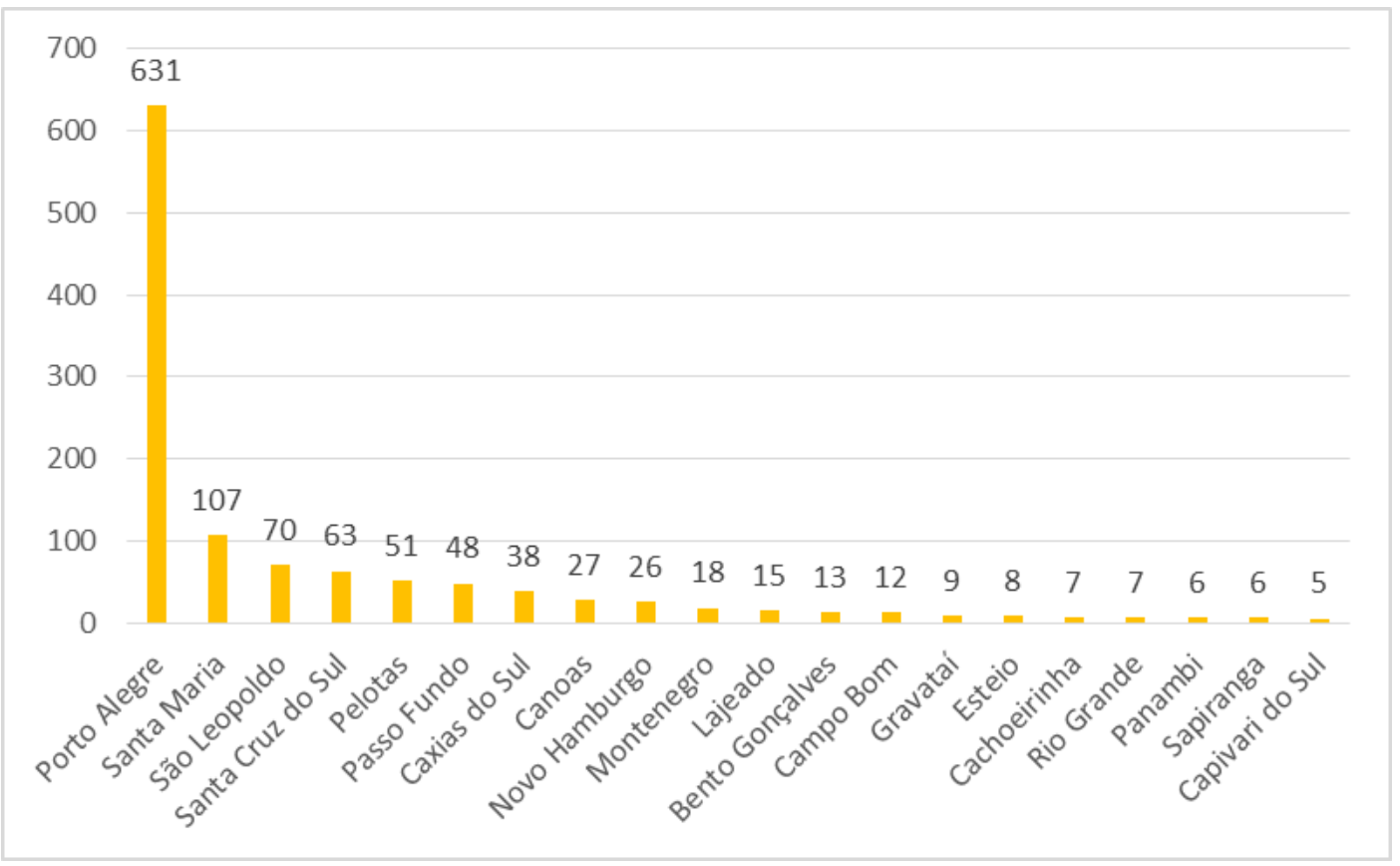

Fonte: INPI (2017).

Em 17 anos, foram depositados 1.258 registros de programa de computador, sendo que 631 saíram dos municípios que concentram o maior número de firmas de TI, conforme o Gráfico 1. Verifica-se que os registros se concentram no eixo Porto Alegre-Caxias do Sul e nas cidades do interior já mencionadas; ocorrendo, novamente, uma forte relação entre essa variável e a presença de firmas de TI. Aqui, observa-se que, ainda que tímida, a inovação existe, o que significa que informação, conhecimento e aprendizagens estão ocorrendo nestes territórios.

A concentração de TI e centralidades urbanas no Rio Grande do Sul

A variável centralidade urbana foi utilizada a partir do documento Regiões de Influência das Cidades-REGIC, de 2007, organizado pelo IBGE. Ele é uma classificação de tipologias de cidades segundo sua centralidade regional e sua área de influência. Na definição das centralidades, são usadas informações referentes: a informações de subordinação administrativa no setor público federal, à localização das sedes e filiais de empresas, à oferta de ligações aéreas, a deslocamentos para internações hospitalares, a áreas de cobertura das emissoras de televisão, à oferta de ensino superior, à diversidade de atividades comerciais, à oferta de serviços bancários, à presença de domínios de Internet etc. Além disto, são levadas em conta as informações de fluxos materiais e imateriais entre cidades. Com isso, a REGIC estabelece cidades que possuem hierarquias diferentes. Os níveis de maior influência para menor influência são metrópoles, capitais regionais A, B e C, centros sub-regionais, centros zonas e centros locais. Comparando as 20 cidades que abrigam o maior número de empresas de Ti com sua posição na REGIC, obtemos a Quadro 2, na qual se registra que, entre os 20 municípios com mais atividades de TI, estão uma metrópole, cinco capitais regionais e quatro centros sub-regionais. 
Quadro 2. Os 20 (vinte) maiores municípios com firmas em TI e sua classificação segundo o REGIC, 2007.

\begin{tabular}{|l|l|}
\hline Município & Classificação na REGIC \\
\hline & \\
1-Porto Alegre & Metrópole \\
2-Caxias do Sul & Capital Regional B \\
3-Novo Hamburgo & $*$ \\
4-Canoas & $*$ \\
5-Sao Leopoldo & $*$ \\
6-Pelotas & Capital Regional C \\
7-Santa Maria & Capital Regional B \\
8-Passo Fundo & Capital Regional B \\
9-Gravataí & $*$ \\
10-Cachoeirinha & $*$ \\
11-Santa Cruz do Sul & Centro Sub-Regional A \\
12-Bento Goncalves & Centro Sub-Regional A \\
13-Lajeado & Centro Sub-Regional A \\
14-Esteio & $*$ \\
15-Erechim & Centro Sub-Regional A \\
16-Montenegro & $*$ \\
17-Rio Grande & Capital Regional C \\
18-Campo Bom & $*$ \\
19-Sapiranga & $*$ \\
20-Guaíba & $*$ \\
\hline
\end{tabular}

Fonte:REGIC/IBGE (2017). Os municípios com * pertencem à Região Metropolitana de Porto Alegre.

Os dez municípios que restam fazem parte da Região Metropolitana de Porto Alegre; isto indica que as firmas em TI ou estão na RM, ou estão em capitais regionais $\mathrm{B}$ ou $\mathrm{C}$ ou em centros sub-regionais. Dado que permite uma relação da TI a locais que possuem infraestrutura material, não só para transportes, mas também para centros que concentram recursos diferenciados dentro do Estado.

\section{CONCLUSÕES}

Iniciou-se o texto apontando que a globalização é uma nova fase do Capitalismo, a qual acirrou a competividade. E a inovação é considerada a chave para enfrentar essa situação. Para que isto aconteça, novas estratégias devem ser adotadas, e a transformação de informação em conhecimento torna-se fundamental, como estes processos estão correlacionados, mas são diferentes, o foco da economia tem sido tornar estes processos uma coisa só, para gerar produtos novos para o mercado.

E hoje pode-se apontar que existe uma nova economia que se constrói baseada no setor de serviços, e está ligada ao imperativo da inovação. A TI é uma das atividades mais emblemáticas desta nova economia, porque ela gera inovação, direta e indiretamente, e, rapidamente, coloca a inovação em circulação. Com isto, contribui para que a inovação criada se torne rapidamente obsoleta, ou seja, ao ser rapidamente difundida pela Internet, a inovação criada é superada por novas propostas. Ademais, ela fomenta os fluxos, flexibiliza tempo e espaço, até mesmo o espaço físico que opera é pequeno, versátil. A TI está integrada à flexibilidade e versatilidade que a nova economia global anuncia. Contudo, esse processo ainda não é dominante no mundo (vide dados Fortune) e também não o é no Brasil, mas está presente e não mostra sinais de contração, ao contrário.

O estudo efetuado no Rio Grande do Sul buscou identificar a localização da TI e quais as características dos territórios em que esta atividade se desenvolve. E revelou que o espaço escolhido é o metropolitano, isto é, a TI no Rio Grande do Sul se estabelece com vigor em Porto Alegre e no entorno, revelando forte aglomeração. E os municípios que se destacam fora desse eixo são poucos, a saber: Passo Fundo, Santa Maria, Pelotas Santa Cruz e Caxias do Sul, e este último está muito próximo do eixo metropolitano.

As empresas estão ligadas a atividades rotineiras, que envolvem suporte técnico, tratamento de dados e manutenção de portais. Fato que não é positivo, pois, segundo o que é apontado no trabalho, a competitividade dos países vem justamente das atividades que possam gerar inovação. O Rio Grande do Sul, se quiser se alinhar ao imperativo econômico deste século, deve buscar fortalecer os empregos e as empresas de TI nas atividades potencialmente inovadoras.

Considerando que a atividade de TI pode atuar a distância, o estudo buscou discutir quais as razões para concentração, e, para tanto, fundamentou-se na premissa que os recursos que os territórios precisam hoje, para permitir a competividade das firmas, é carregado de informação e conhecimento. Iniciou-se pela discussão da presença banda larga fixa de Internet, considerando-se, incialmente, que a concentração de empresas de TI poderia estar ligada à disponibilidade de Internet, afinal, estamos diante de uma nova rede técnica. Mas esta premissa foi descartada pelo estudo, a Internet está presente em todo território do Rio Grande 
do Sul. E a fibra em alta velocidade (>34 Mpbs) está presente na maior parte dos municípios. Assim, os dados apresentados revelam que existe disponibilidade de Internet, além disto, foi examinado que a infraestrutura existe, a oferta que não é materializada pelos grupos que controlam as tecnologias, isto porque não existe a demanda.

Continuando os estudos, foram investigadas as variáveis PIB (indicando presença de capital) e população (indicando população que faz e necessita de inovação). Os dados revelaram que, nos territórios nos quais estão as firmas e empregados de TI, é onde está a maior concentração de população e onde existe maior PIB. O que revela que a TI está onde existe demanda e tem movimento, pessoas pensando em inovações para outras pessoas e empresas, e onde existe capital para pagar por isto; o que, na visão do estudo, revela agitação, barulho.

Mas se, de fato, a nova economia se constitui dentro da premissa da informação e do conhecimento, tanto as profissões devem buscar conhecimento e informação, como os territórios devem conter isto. E, para avaliar esta ideia, o trabalho apresentou as variáveis graduação e depósito de programas de computador. Verificou-se que a TI é uma atividade que tem profissionais que atingem expressivos índices de escolaridade, mais de $50 \%$ deles possuem curso superior ou estão cursando. E, nos territórios em que está a TI, é onde existem maiores números de graduados nesta área. Aperfeiçoando os dados para a análise, verificou-se que, onde existe maior número de depósito de programas de computador, é onde está a TI. Diante disto, é possível afirmar que estes territórios são carregados de informação e conhecimento.

Completando a análise, investigou-se a rede urbana, a partir de dados da REGIC. A comparação dos dados com a presença de empresas e empregados de TI revelou que os municípios com maior influência na rede urbana, ou seja, onde está o comando político, econômico, financeiro e cultural do Estado, são os territórios com maior número de empresas de tecnologias de informação.

E esta constatação permite alargar a tese do face-toface, mostrando que o "burburinho" é acompanhado por outros tipos de "barulho", o das pessoas divulgando conhecimentos, das pessoas aprendendo, das pessoas se deslocando, das pessoas buscando inovações. E, desta forma, criam uma efervescência.

Assim, o estudo expõe que a atividade de TI no Rio Grande do Sul segue as novas lógicas dos serviços, e da nova economia, buscando os grandes centros. E este fato tem implicações muito sérias do ponto de vista socioespacial, pois os territórios escolhidos pela nova economia parecem ser seletivos. E esta seletividade pode agravar desigualdades territoriais já existentes em diversas escalas no Brasil.

\section{REFERÊNCIAS}

ANATEL - Agência Nacional de Telecomunicações-. Brasília: 2016. Disponível em https://www.anatel.gov.br/paineis/acessos/bandalarga-fixa

ASHEIM, Björn; GRILLITSCH, Markus; TRIPPL, Michaela. Regional Innovation Systems: Past Presence - Future. Doloreux D.; Shearmur, R.; Carrincazeaux (eds) In: 'Handbook on the Geography of Innovation', Edward Elgar, UK/US, p.45-62,

2016).https://doi.org/10.4337/9781784710774.00010

CASTELLS, Manuel. A sociedade em rede. São Paulo: Paz e Terra, 1999.

CONCLA - Comissão Nacional de Classificação. Rio de Janeiro: IBGE. 2006. Disponível em: https://concla.ibge.gov.br/

IBGE. Contas Nacionais Trimestrais (2010-2017). Rio de Janeiro: IBGE. 2017. Disponível em: https://sidra.ibge.gov.br/pesquisa/cnt/tabelas

IBGE. CENSO DEMOGRÁFICO 2010. Rio de Janeiro: IBGE. 2010. Disponível em: https://www.ibge.gov.br/estatisticas/sociais/populaca o/9662-censo-demografico-2010

IBGE. Produto Interno Bruto dos Municípios. Rio de Janeiro: IBGE. 2017. Disponível em: https://www.ibge.gov.br/estatisticas/economicas/cont as-nacionais/9088-produto-interno-bruto-dos-

municipios

IBGE. Regiões de influência das cidades REGIC 2007. Rio de Janeiro: IBGE. 2007. Disponível em: https://biblioteca.ibge.gov.br/visualizacao/livros/liv4 0677.pdf

INEP - Instituto Nacional de Estudos e Pesquisas Educacionais Anísio Teixeira.Censo de educação superior Brasília: INEP. 2016. Disponível em: http://portal.inep.gov.br/web/guest/microdados

INPI - Instituto Nacional de Propriedade Intelectual.(2000-2017). Rio de janeiro: INPI. 2017. Disponível em https://www.gov.br/inpi/pt-br/centralde-conteudo/estatisticas

KNOX, Paul; AGNEW John; MCCARTHY, Linda. The geography of the world economy. New York: Routledge, 2014.

KON, Anita. Economia de Serviços: Teoria e evolução no Brasil. Rio de Janeiro, Elsevier, 2004.

LUNDVALL, Bengt-Ake; BORRÁS, Susana. The globalising learning economy: Implications for in innovation policy. Luxembourg: Office for Official Publications of the European Communities, 1998.

MCCANN, Philip; ORTEGA-ARGILÉS, Raquel Smart Specialization, Regional Growth and Applications to European Union Cohesion Policy. Regional Studies. V. 49, 1291-1302, 2015. https://doi.org/10.1080/00343404.2013.799769

MÉDEZ, Ricardo. El territorio de las nuevas economías metropolitanas. Revista eure (Vol. XXXIII, No 100), pp. 51-67. Santiago de Chile, diciembre de 2007. https://doi.org/10.4067/S0250-71612007000300004 
OLIVEIRA, Giovana Mendes de. O uso do território para inovação. Mercator. Fortaleza, v.13, p.53 - 60, 2014. https://doi.org/10.4215/RM2014.1302.0004

OLIVEIRA, Giovana Mendes de. Uma análise quantitativa das mulheres no mundo do trabalho das tecnologias da informação no Brasil In: Género y TIC.1 ed.Chiapas, México: El Colegio de la Frontera Sur,, 2018, v.1, p. 30-61.

OLIVEIRA, Giovana Mendes. The study of the territory and its resources among scientific and technical informational: information technologies in Rio Grande do Sul, BRAZIL. International Journal of Latest Research in Science and Technology, v. 5, 2831, 2016.

PEREIRA, Alex Sandro Amaral; OLIVEIRA, Giovana Mendes. De. Apontamentos geográficos sobre a nova economia: os parques tecnológicos do rio grande do sul em 2018. Geographia Meridionalis, v.5, p.174 194, 2020.

RAFFESTIN, Claude. Por uma Geografia do poder. São Paulo: Ática, 2011.

RAIS - Relação Anual de Informações Sociais. Brasília: Programa de disseminação das estatísticas do trabalho. Ministério do Trabalho, 2016. Disponível em: http://pdet.mte.gov.br/acesso-online-as-bases-dedados.

SANTOS, Hélder Fernando da Costa. Em busca do território perdido: conhecimento, aprendizagem e inovação. Porto: Cadernos curso de doutoramento em Geografia, FLUP,289-329, 2009.

SANTOS, Milton. Dinheiro e território. GEOgraphia. Ano. 1, No 1, 7-13, 1999.

SANTOS, Milton. Técnica, espaço, tempo: globalização e meio técnico-científico informacional. São Paulo: Hucitec, 1994.

STORPER, Michael; VENABLES, Anthony. O burburinho e força da cidade. In: DINIZ, Clélio C.; LEMOS, Mauro B. Economia e território. Belo Horizonte: Editora UFMG, 21-56, 2005.

TAKEUCHI, Hirotaka; NONAKA, Ikuro. Gestão do Conhecimento. Porto Alegre: Bookman, 2008.

\section{CONTRIBUIÇÃO DOS AUTORES}

Geovana Mendes de Oliveira planejou e executou a pesquisa e a coleta de dados, bem como escreveu os resultados e fez a revisão. 